\title{
In Vitro Anti-AngiogenicActivityand Anti-Cancer Properties of ThiadiazoleCoumarin Derivative Compound
}

\author{
Sarah $^{1}$. F. Faisal; Dhamraa ${ }^{2}$. W. AL-Dulaimi; Hussein ${ }^{3}$. M. Baharetha; Amin ${ }^{4}$. \\ M. Sh. Abdul Majid* and Hasnah ${ }^{5}$ Osman** \\ Eman Laboratory, Department of Pharmacology, School of Pharmaceutical Sciences, UniversitySains \\ Malaysia, Penang 11800, Malaysia \\ *Corresponding Author (Associate Professor)ACRF Department of Cancer Biology and Therapeutics, The John \\ Curtin School of Medical Research, Australian National University \\ **Deputy Dean (Academic, Students and Alumni), School of Chemical Sciences, University Sains Malaysia, \\ Penang 11800, Malaysia
}

\begin{abstract}
The thiazole ring of coumarin derivativesis a heterocyclic structure that attracts most organic and medical chemists to synthesise these compounds. Five of the newly synthesized thiazolecoumarin derivative compounds(TCD)were screened in MTT assay for in vitro antitumor activity against three cancer and one normal cell lines. A significant inhibition of cancer cells was observed with compound (4)that displayed a significant cytotoxic effect against HCT 116 cells with $\left(29.3 \pm 1.9 \mu \mathrm{M} \mathrm{ml}^{-1}\right)$ of the Ic50 value. Furthermore, we have investigated the effect of the compound on angiogenesis in vitro and Ex vivousing tube formation and rat aorta ring assay respectively. The results showed that the compound inhibited the tube formation after plating endothelial cells on Matrigel and showeda significant inhibition of micro vessels outgrowth of the rat aortic ring assay in a dose-dependent manner $(P<0.05)$.
\end{abstract}

Keywords:thiazolecoumarin compounds, anti-angiogenesis, MTT, ring assay, tube formation assay in vitro

\section{Introduction}

Colon carcinoma is the second common cause of death worldwide and third most commonly diagnosed, the ratios is expected to increase up to $60 \%$ by 2030[1]. The common symptoms of colon cancers included alteration in bowel habit, rectal bleeding, abdominal pain and weight loss [2]. Thecharacterization and isolation of colon cancer cells may help to devise novel diagnostic and therapeutic procedures [3]. The therapeutic strategies currently available for colon cancer treatment are surgery, chemotherapy, and radiotherapy.Pre-clinical studies showed that tumours induce the developing of new vessels from the surrounding vasculature, this process is vital for the growth of tumours; therefore it was hypothesised that the inhibition of angiogenesis could suppress tumour growth in humans. It was reported that anti-angiogenetic drug is an efficient therapy for eliminating colon cancers[4]. Men younger than age 50 are at higher risk for colon cancer. Coumarin is naturally synthetized phenolic compounds by the plant as an efficient chemical defence system against traumatic injury, microorganism invasion and insect damage. Also it has beneficial effects on human health, such as reducing the risk of cancer, cardiovascular diseases, diabetes, and brain diseases[5]. It possessed fused benzene and $\alpha$-pyrone rings, which are considered as the basic molecules of several families of derivative. Moreover, coumarin considers the parent molecule of warfarin, which acts as vitamin $\mathrm{K}$ antagonist, Warfarin is clinically used as an anticoagulant andit is widelyused as a rodenticide[6]. Biocompatibility study of coumarin derivatives is necessary to discover and determine their therapeutic effect and toxicity level. The different toxicity value of the coumarin can be related to the presence of different hydroxyl group in its structures. A substitutions can occur at any of the six available sites of the basic coumarin nucleus to increase its multiple biological properties [7].Coumarincompounds containing thiazole ring system are known to possess several pharmacological properties, such as analgesic, anticonvulsant, anti-parasitic, anti-inflammatory, antibacterial and herbicidal[8]. Coumarin and its derivatives are well distributed in nature, they exhibit a broad pharmacological profile, including antioxidant, anti-inflammatory, anticancer properties and the scavenging activity [5, 9]. Tumors employed angiogenesis to generate the vascular blood capillaries from pre-existing vessel needed for nutrients and oxygen supplements.Many cancer drugs aimed to inhibit tumor angiogenesis through molecular targets, intracellular signaling pathways and inhibiting multiple cell types. The angiogenesis inhibitors may directly inhibit target endothelial cells and avoid their capability to proliferate, disturb the production of angiogenic factors and inhibited angiogenesis signalling pathways, some other anti-angiogenic agents are nonspecific or with unknown mechanism [10].Some new synthesized coumarin derivatives displayed appreciable anticancer against leukemia, colon cancer and breast cancer cell lines [11] and anti- angiogenesis activities [12]. Tube formation assay have been used as a useful tool for the evaluation of cancer angiogenesis.Tube formation occurs quickly. The endothelial cells beginning to align within $1 \mathrm{hr}$ and lumen- 
containing tubules started to appear within $2 \mathrm{hr}$. Tubes can be visualized using a phase contrast inverted microscope. The number of branches, loops/meshes, or tubes length can be easily quantified as a measure of in vitro angiogenesis [13]. Ex vivoanti-angiogenesis assay first conducted usingrat aortic ring assay[14].It is an $e x$ vivo physiologically relevant assay with obvious advantages over other in vitro methods. It is relatively inexpensive and quick to perform, with many aortic ring available from few animal[15]. The anti-angiogenic potential ofCoumarincompound was studied in vitro and Ex vivo(aortic ring sprouting assay)the compound significantly inhibited the growth of the EAHY sprouts in dose dependent manner[16].

\section{Materials and Methods}

All cell cultures and their reagents were procured from Gibco (USA). Phosphate buffered saline, trypsinwere procured from Sigma (Germany). MTT [3-(4,5dimethylthiazol-2-yl)- 2,5diphenyl tetrazolium bromide] purchased from Sigma-Aldrich (USA). Dimethyl sulfoxide (DMSO) was procured from Fluka (USA).

The EAHY cell line, human colorectal carcinoma cell line HCT-116 and human hormone sensitive invasive breast cancer cell line MCF-7 were purchased from ScienCell (USA), human lung cancer cell line (A459) was purchased fromATCC (USA).EAHY and MCF-7 cells were maintained in DMEM (ESCO- BSC, Singapore). HCT-116 cells were maintained in RPMI, whereas A459 cells were maintained in F12K. The culture was in a humidified incubator at $37^{\circ} \mathrm{C}$ supplied by $5 \% \mathrm{CO}_{2}$. All the cell culture work was conducted in a sterile condition using a Class II biosafety cabinet (ESCO, USA).

\section{Chemical compound preparation}

The synthesis and characterization of the pure thiadiazolecoumarin derivative compound was done in the organic synthesis laboratory.SCS.USM (Samina Khan Yusuf Zai, PhD Thesis, USM, 2015).Gas Chromatography-Mass Spectrophotometry (GC/MS) analysis was carried out. The compound was screened for its cytotoxic activities against cancer and normal cell lines. The TCD(4) compoundwith the following formula:

Figure 1: Thiadiazolecoumarin derivative compound (4)

The MTT cytotoxicity assay was performed according to the usual procedure of cell culturing. Briefly, $100 \mu \mathrm{L}$ of different cell lines were seeded in a 96 well plate at $1.5 \times 10^{4}$ cells per well and allowed toattach overnight. For screening process, the cells (70-80\% confluence) were treated withTCD(4) compoundat 25, 50, $75,100,150$ and $200 \mu \mathrm{Mml}^{-1}$. After $48 \mathrm{~h}$ of treatment, MTT solution prepared at $5 \mathrm{mg} / \mathrm{mL}$ in sterile PBS.Then the solution was added to each well andincubated at $37^{\circ} \mathrm{C}$ in $5 \% \mathrm{CO}_{2}$ for $4 \mathrm{~h}$. The absorbance was measured by the TECAN microplate reader at the primary wave length of $570 \mathrm{~nm}$ and the reference wavelength was $620 \mathrm{~nm}$. Each plate contained the negative control,the samples and the blank. DMSO (1\% v/v) was used as the negative control. The assay was repeated three times, and the results were presented as a mean percent ofinhibition compared to the negative control $\pm \mathrm{SD}(\mathrm{n}=4)$.

Tube formation assay is an in vitro quantitative assay performed to evaluate the anti-angiogenic activity of the chemical compound and to confirm the ability of EAHY to form capillary-like structures on a matrigel matrix, where the cells adhere into the basement membrane, they start to migrate and differentiate to form tubes-network [17].Briefly, the matrigel matrix was allowed to polymerizefor 45 min at $37^{\circ} \mathrm{C}$ in $5 \% \mathrm{CO}_{2}$. EAHY were trypsinized and seeded in $100 \mu$ l of DMEM containing various concentrations of TCD $(4)$ compound in triplicates. After $6 \mathrm{~h}$, the tubular networks in the wells were formed and photographed by a digital camera (Leica, DC300, USA) which is connected to a light inverted microscope at $4 \mathrm{X}$ magnification. The quantitative estimation of tube formation inhibition was achieved by using the Scion Image analysis program to measure the area occupied by tubular structures. The results were presented as the percentage of inhibition mean \pm SD. It was calculated according to the formula:

$\%$ of inhibition of tube formation= [1-(Area A/Area S $)] \times 100$

Where: Area A: the area of tubules in the treated wells

Area S: the area of tubules in the untreated wells. 
The rat aortic ring assay was performed following previous method by [18] with slight modifications. Briefly, thoracic aortas were excised from euthanized male rats, they were cross sectioned into small rings (of 1 $\mathrm{mm}$ in length) then each ring was seeded individually in 48-wells plate in $300 \mu \mathrm{L}$ serum free M199 media supplemented with fibrinogen $\left(3 \mathrm{mgml}^{-1}\right)$ and $5 \mathrm{mgml}^{-1}$ aprotinin. Ten microliters of thrombin was added into each well and incubated at $37^{\circ} \mathrm{C}$ for 90 min to solidifyand to support embedding of the rings in the lower layer. A second layer (M 199 medium supplemented with 20\% HIFBS, 0.1\% غ́-aminocaproic acid, 1\% L-Glutamine, $2.5 \mu \mathrm{g} \mathrm{ml}{ }^{-1}$ amphotericin $\mathrm{B}$, and $60 \mu \mathrm{gml}^{-1}$ gentamicin) was added into each well (300 $\mu \mathrm{L} /$ well) with various concentrations $(5,10,20,40,80$ and $160 \mu \mathrm{M})$ were used for calculating IC50 (median inhibitory concentration) of the active compound(TCD 4).Suramin and DMSO (1\%) were used as positive and negative controls, respectively. On day four, the medium was replaced with a fresh medium containing the test materials. On day five, the micro vessels of the aortic rings were photographed using EVOS f1 digital microscope (Advanced Microscopy Group, USA) (40X magnification) and the length of blood vessels growth from the primary tissue was measured using Leica Quin software. All treatments were conducted with four replications and the results are presented as mean \pm SD. The differences among groups were compared by a one-way analysis of variance (ANOVA) using GraphPad Prism6 and considered significant at $\mathrm{p}<0.05$. The inhibition of blood vessels formation was calculated using the formula:

$\%$ blood vessels inhibition $=[1-(\mathrm{A} 0 / \mathrm{A})] \times 100$, Where; $\mathrm{A} 0=$ distance of blood vessels growth in treated rings in $\mu M, \mathrm{~A}=$ distance of blood vessels growth in the control in $\mu M$.

\section{Results}

The anti-proliferative activity of TCD(4)was tested againsttumour cell lines and one normal cell line using the MTT assay. The inhibitory concentrations (IC50) values were calculated for each cell line and the values are presented in Table 1. The compound showed different cytotoxic activities, on colon cancer (HCT 116) $\left(\mathrm{IC} 50=29.0 \pm 1.9 \mu \mathrm{M} \mathrm{ml}^{-1}\right)$ and it displayed poor cytotoxic activities against breast (MCF-7) cell line with (IC50 $112.77 \pm 4.22 \mu \mathrm{M} \mathrm{ml}^{-1}$ ) and lung cancer (A459) cell line with (IC50=104.53 $\pm 2.27 \mu M \mathrm{ml}^{-1}$ ), whereas it displayed a moderate cytotoxicity against human endothelial cells (EAHY) with (IC50 $70.4 \pm 1.8 \mu M \mathrm{ml}^{-1}$ ). Table (1) shows thegraphical illustration of the dosedependent anti-proliferative effect of TCD(4) against tested cell lines.

Table 1: IC50 Values of ThiadiazoleCoumarin Derivative Compound (4) on various human cancer cell lines with the standard controls

\begin{tabular}{|cc|}
\hline CELL LINES & IC50 $\square M$ ml $^{-1}$ \\
\hline HCT 116 & $29.0 \pm 1.9$ \\
\hline MCF-7 & $112.77 \pm 4.22$ \\
\hline A459 & $104.53 \pm 2.27$ \\
\hline EAHY & $70.4 \pm 1.8$ \\
\hline
\end{tabular}

Data show in Figure 1 indicate that EAHY cells forms tube-like structure networks in a matrigel matrix within $6 \mathrm{~h}$. Anti-angiogenic effect of thiadiazolecoumarin derivative compoundwas confirmed by studying the effect on differentiation of EAHYs on matrigel matrix. Treatment of EAHY with TCD(4) compound inhibited the growth factors induced differentiation in a dose-dependent manner. Compoundconcentrations with $\left(35\right.$ and $70 \mu M \mathrm{ml}^{-1}$ ) reduced the area occupied by the network structures with inhibitory effect of $34.80 \pm 12.86$ and $42.40 \pm 12.09 \%$, respectively. Whereas, the high concentration of TCD $(4)$ compound $140 \mu \mathrm{Mml}^{-1}$ showed $51.90 \pm 5.08 \%$ of inhibition. Similarly, the positive control of Suramin was completely abrogated endothelial tube formation while the untreated EAHYcells showed obvious tubes formation on matrigelas a negative control.
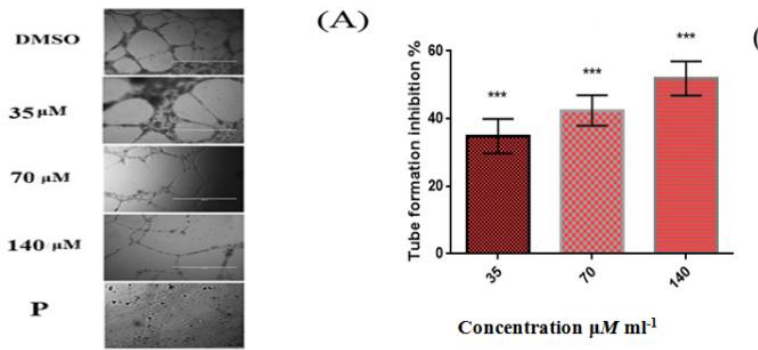

(B)

Figure 1: (A)Images of EAHYs Matrigel tube formation assay. Thidiazolecoumarin derivative compound (4) inhibits matrigel tube formation. EAHYs were treated with $0.5 \% \mathrm{DMSO}, 35 \mu \mathrm{mll}^{-1}, 70 \mu M \mathrm{ml}^{-1}, 140 \mu M \mathrm{ml}^{-}$

${ }^{1}$ of the compound and Suramin $100 \mu \mathrm{M} \mathrm{ml}^{-1}$, (B) the graph shows the dose response relationship of the compound on tube formation assay.

DOI: $10.9790 / 3008-120103106110 \quad$ www.iosrjournals.org $\quad 108 \mid$ Page


The 3D rat aortic ring assay was performed to quantify the anti-angiogenic potential of the chemical compound (thiadiazolecoumarin derivative 4)it was done by measuring the micro vessels sprouted from rat aortic rings. The experiment was carried out with six concentrations $(5,10,20,40,80$ and 160), the obtained medium inhibitory effect (IC50) was $46.493 \mu \mathrm{M} \mathrm{ml}^{-1}$. The inhibition of micro vessels from explants rat aorta treated with the compound was significantly compared to the untreated micro vessels. Images show in Figure (2) indicatesthat the micro-vessels growth from the untreated aortic rings (0.5\% DMSO) did not display any inhibitory effect. On the contrary, treatment with $\mathrm{TCD}(4)$ compound (Figure 3) shows the dose response curve of the compound on rat aortic ring assay and the concentration--activity curve of the compound.
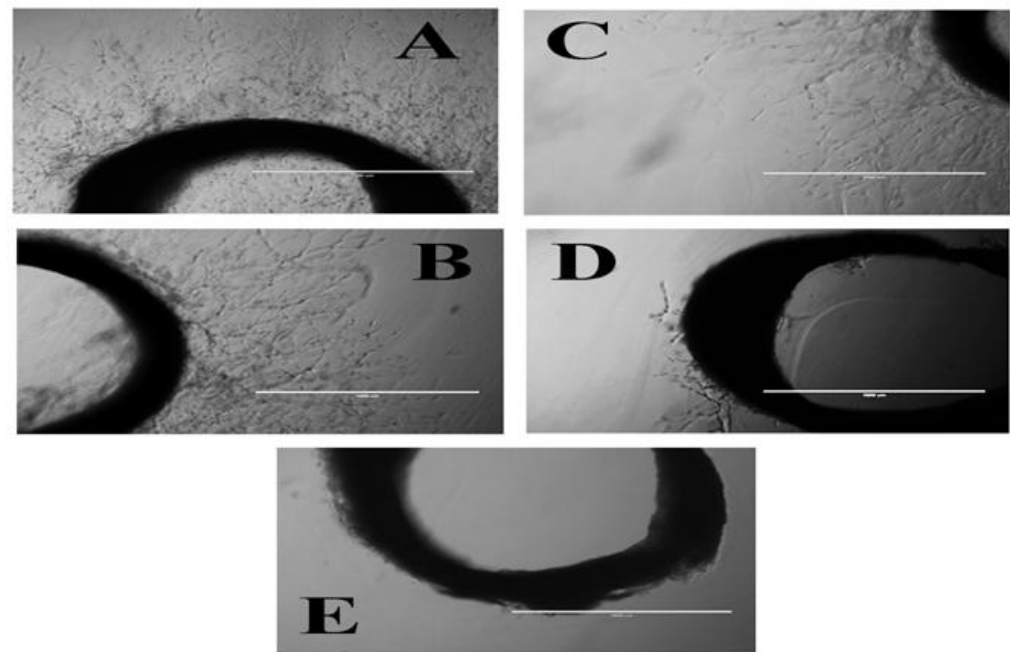

Figure 2: Photos showing the anti-angiogenic effect of TCD 4 against sprouting of micro-vessels in rat aortic explants. Images were taken on the 5th day of the experiment using an inverted phase-contrast microscope at 40 $\mathrm{X}$ magnifications. (A) $0.5 \% \mathrm{DMSO}$ as a negative control showing extensive growth of micro-vessels. (B) TCD (4) $5 \mu \mathrm{M} \mathrm{ml}^{-1}$. (C) TCD(4) $40 \mu M \mathrm{ml}^{-1}$. (D) TCD (4) $160 \mu M \mathrm{ml}^{-1}$. (E) Suramin as a positive control.
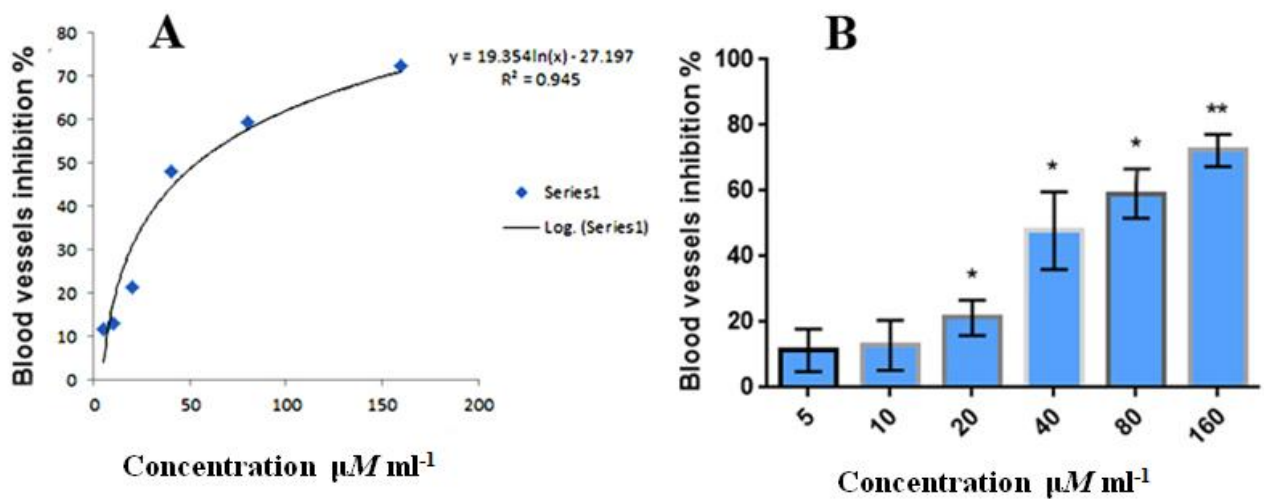

Figure 3: Graphical representation of anti angiogenic activity of Thiadiazolecoumarin derivative (4). (A) Concentration-activity curve of the compound concentrations. (B) Dose response curve of the extracts on rat aortic ring assay. The data was represented as mean $\pm \mathrm{SD}$. $* \mathrm{P}<0.05$ and $* * \mathrm{P}<0.01$.

\section{Discussion}

In this study, two angiogenesis platform were performed to assess the antiangiogenic effect of TCD(4).In vitro assay, EAHYs were used as a model cell line of angiogenesis because it forms the internal tubelike structure of the blood vessels. The result showed that $\operatorname{TCD}(4)$ compound has a slight cytotoxicity towards endothelial cells with IC50=70.3 $\pm 1.8 \mu \mathrm{Mml}^{-1}$. Subsequently, TCD(4) inhibited tube-like structure networks ina matrigel matrix in a dose dependent manner (Figure 1.0),during the last steps of angiogenesis, endothelial cells formed tubuleslike structure, where they adheres into the basementmembrane, then they migrate and differentiate to form tubes-network [2].Thus, Inhibition of tube-like structures of endothelial cells explained a valuable approach of antiangiogenic potency of the compound on vascularization. Moreover, rat aortic ring assay was used in this study as ex vivo platform to evaluate the effects of thiazolecoumarin derivative compound on the growth of new blood vessels (Angiogenesis)from the explanted tissue. The results showed that TCD(4)perturbed the newblood vessels formation from rat aortic ring explants with IC50 $46.493 \mu M \mathrm{ml}^{-1}$. 
In Vitro Anti-Angiogenic Activity and Anti-Cancer properties of Thiadiazolecoumarinderivative ..

Subsequently, the results of the MTT assay on EAHYs and rat aortic ring assay suggest that the compound hasantiangiogenic effect and a slight cytotoxic activity on normal cells. Since angiogenesis is a process that is generally down regulated in the normal condition, the antiangiogenic approach of cancer therapy should be selective and nontoxic also may not lead to side effects even after prolonged exposure [3]. In this study, TCD(4)exhibited a dose dependent antiproliferativeactivity against colorectalcancercells.Moreover, the compound consideredantiangiogenic on tube formation andrat aortic ring assay.Several studies indicate that these compounds have promising capability to suppress certain types of cancer cells by inducing apoptosis pathways.Overall, the TCD (4) exhibits a significant activity against colorectal cancer cells through a mechanism that appears to involve angiogenesis suppression and the inducing of apoptosis.

\section{Conclusion}

In this study, we detected that the TCD(4)was found to exert significant anti-angiogeniceffects. The compound inhibited angiogenesis in vitro and Ex vivo by disrupting endothelial cell tube formation and vessel formation in ring assay,it was suggested that this compound may be a promising one for a chemotherapeutic treatment. More studies are in progress to investigate the toxicity profile of thiazole derivatives compounds and theanti-canceractivity.

\section{Acknowledgements}

Sarah F Sallaland Hussein M.Baharetha would like to acknowledge Institute of Postgraduate Studies, UniversitiSains Malaysia for providing USM Fellowship [2/15] and [1/10].

\section{References}

[1]. Arnold, M., M.S. Sierra, M. Laversanne, I. Soerjomataram, A. Jemal, and F. Bray, Global patterns and trends in colorectal cancer incidence and mortality. Gut, 2016: p. gutjnl-2015-310912.

[2]. Adelstein, B.-A., P. Macaskill, S.F. Chan, P.H. Katelaris, and L. Irwig, Most bowel cancer symptoms do not indicate colorectal cancer and polyps: a systematic review. BMC gastroenterology, 2011. 11(1): p. 1.

[3]. Ricci-Vitiani, L., D.G. Lombardi, E. Pilozzi, M. Biffoni, M. Todaro, C. Peschle, and R. De Maria, Identification and expansion of human colon-cancer-initiating cells. Nature, 2007. 445(7123): p. 111-115.

[4]. Lin, S.-P., Y.-T. Lee, S.-H. Yang, S.A. Miller, S.-H. Chiou, M.-C. Hung, and S.-C. Hung, Colon cancer stem cells resist antiangiogenesis therapy-induced apoptosis. Cancer letters, 2013. 328(2): p. 226-234.

[5]. Borges Bubols, G., D. da Rocha Vianna, A. Medina-Remon, G. von Poser, R. Maria Lamuela-Raventos, V. Lucia Eifler-Lima, and S. Cristina Garcia, The antioxidant activity of coumarins and flavonoids. Mini reviews in medicinal chemistry, 2013. 13(3): p. 318334.

[6]. Zacchigna, M., G. Di Luca, F. Cateni, and V. Maurich, Improvement of warfarin biopharmaceutics by conjugation with poly (ethylene glycol). European journal of pharmaceutical sciences, 2004. 23(4): p. 379-384.

[7]. Rahman, F.S.A., S.K. Yusufzai, H. Osman, and D. Mohamad, Synthesis, Characterisation and Cytotoxicity Activity of Thiazole Substitution of Coumarin Derivatives (Characterisation of Coumarin Derivatives). Journal of Physical Science, 2016. 27(1): p. 7787.

[8]. Kashyap, S.J., V.K. Garg, P.K. Sharma, N. Kumar, R. Dudhe, and J.K. Gupta, Thiazoles: having diverse biological activities. Medicinal Chemistry Research, 2012. 21(8): p. 2123-2132.

[9]. Witaicenis, A., L.N. Seito, A. da Silveira Chagas, L.D. de Almeida, A.C. Luchini, P. Rodrigues-Orsi, S.H. Cestari, and L.C. Di Stasi, Antioxidant and intestinal anti-inflammatory effects of plant-derived coumarin derivatives. Phytomedicine, 2014. 21(3): $\mathrm{p}$. 240-246.

[10]. Finley, S.D., L.-H. Chu, and A.S. Popel, Computational systems biology approaches to anti-angiogenic cancer therapeutics. Drug discovery today, 2015. 20(2): p. 187-197.

[11]. Paul, K., S. Bindal, and V. Luxami, Synthesis of new conjugated coumarin-benzimidazole hybrids and their anticancer activity. Bioorganic \& medicinal chemistry letters, 2013. 23(12): p. 3667-3672.

[12]. Kaur, M., S. Kohli, S. Sandhu, Y. Bansal, and G. Bansal, Coumarin: a promising scaffold for anticancer agents. Anti-Cancer Agents in Medicinal Chemistry (Formerly Current Medicinal Chemistry-Anti-Cancer Agents), 2015. 15(8): p. 1032-1048.

[13]. DeCicco-Skinner, K.L., G.H. Henry, C. Cataisson, T. Tabib, J.C. Gwilliam, N.J. Watson, E.M. Bullwinkle, L. Falkenburg, R.C. $\mathrm{O}$ 'Neill, and A. Morin, Endothelial cell tube formation assay for the in vitro study of angiogenesis. Journal of visualized experiments: JoVE, 2014(91).

[14]. Nicosia, R.F. and A. Ottinetti, Growth of microvessels in serum-free matrix culture of rat aorta. A quantitative assay of angiogenesis in vitro. Laboratory investigation; a journal of technical methods and pathology, 1990. 63(1): p. 115-122.

[15]. Baker, M., S.D. Robinson, T. Lechertier, P.R. Barber, B. Tavora, G. D'Amico, D.T. Jones, B. Vojnovic, and K. Hodivala-Dilke, Use of the mouse aortic ring assay to study angiogenesis. Nature protocols, 2012. 7(1): p. 89-104.

[16]. Pan, R., X. Gao, D. Lu, X. Xu, Y. Xia, and Y. Dai, Prevention of FGF-2-induced angiogenesis by scopoletin, a coumarin compound isolated from Erycibe obtusifolia Benth, and its mechanism of action. International immunopharmacology, 2011. 11(12): p. 2007-2016.

[17]. Huang, C.-C., W.-Y. Pan, M.T. Tseng, K.-J. Lin, Y.-P. Yang, H.-W. Tsai, S.-M. Hwang, Y. Chang, H.-J. Wei, and H.-W. Sung, Enhancement of cell adhesion, retention, and survival of HUVEC/cbMSC aggregates that are transplanted in ischemic tissues by concurrent delivery of an antioxidant for therapeutic angiogenesis. Biomaterials, 2016. 74: p. 53-63.

[18]. Baharetha, H., Z. Nassar, M. Ahamed, A. Aisha, and S. Alfadly, Use of Nigella sativa Linn. Supercritical Carbon Dioxide Extract for Targeting the Angiogenesis Cascade. Med Aromat Plants, 2016. 5(241): p. 2167-0412.100024. 